\title{
Clinical and histopathological features and prognosis of gastrointestinal adenocarcinomas in Jack Russell Terriers
}

\author{
Aki OHMI ${ }^{1)}$, Koichi OHNO ${ }^{2) *}$, James K. CHAMBERS ${ }^{3)}$, Kazuyuki UCHIDA ${ }^{3)}$, \\ Taisuke NAKAGAWA ${ }^{1)}$, Hirotaka TOMIYASU ${ }^{2)}$ and Hajime TSUJIMOTO' ${ }^{2)}$ \\ ${ }^{1)}$ Veterinary Medical Center, Graduate School of Agricultural and Life Sciences, The University of Tokyo, \\ 1-1-1 Yayoi, Bunkyo-ku, Tokyo 113-8657, Japan \\ ${ }^{2)}$ Department of Veterinary Internal Medicine, Graduate School of Agricultural and Life Sciences, \\ The University of Tokyo, 1-1-1 Yayoi, Bunkyo-ku, Tokyo 113-8657, Japan \\ 3)Laboratory of Veterinary Pathology, Graduate School of Agricultural and Life Sciences, \\ The University of Tokyo, 1-1-1 Yayoi, Bunkyo-ku, Tokyo 113-8657, Japan
}

J. Vet. Med. Sci.

83(2): 167-173, 2021

doi: 10.1292/jvms.20-0421

Received: 9 July 2020

Accepted: 3 December 2020 Advanced Epub:

16 December 2020
ABSTRACT. There has been an increase in the number of Jack Russell Terriers (JRTs) diagnosed with adenomas and adenocarcinomas of the gastrointestinal tract in Japan. This study retrospectively investigated the clinical and histopathological features and prognosis of adenocarcinomas arising in the gastrointestinal tract in JRT dogs. Seven JRTs and 39 dogs of other breeds diagnosed with gastrointestinal adenocarcinoma were included in the study. The most common sites of gastrointestinal adenocarcinoma in JRTs were the pylorus and rectum. On histopathological examination, these adenocarcinomas showed a papillary or tubular growth pattern, and the lesions were confined within the mucosal epithelium and poorly invasive. Among all dogs with gastric adenocarcinoma, the median survival time (MST) for five of the JRTs could not be determined because more than half of the cases remained alive, while the MST for nine non-JRT dogs was 34 days. Among all dogs with adenocarcinoma in the large intestine, the MST for three of the JRTs could not be determined, while the MST for nine non-JRT dogs was 1,973 days. The difference in MST between JRT and non-JRT dogs with gastric adenocarcinoma was significant $(P=0.0220)$. Since gastrointestinal adenocarcinomas in JRTs show distinct characteristics with respect to their clinical features, treatment course, and prognosis, a different surgical and medical treatment plan should be considered compared to the management of gastrointestinal adenocarcinomas in other dog breeds.

KEY WORDS: breed, cancer, canine, carcinoma, dog

Gastrointestinal tumors of epithelial origin are relatively rare in dogs. In a previous study reported in 1977 based on a review of 10,270 canine necropsies at The Animal Medical Center in the United States, the incidences of gastric and intestinal adenocarcinomas were $0.25 \%$ and $0.33 \%$, respectively [22]. According to a 2013 Norwegian survey, gastric adenocarcinoma accounted for only $0.16 \%$ of all canine tumors [26]. Among canine intestinal adenocarcinomas, occurrence in the large intestine is more common than in the small intestine [22].

An increased prevalence of gastric adenocarcinoma has been reported in several breeds including the Belgian Shepherd (Tervueren and Groenendael), Staffordshire Bull Terrier, Rough Collie, Bouvier des Flandres, Standard Poodle, Norwegian Elkhound, and Chow Chow [5, 7, 13, 25, 26, 30]. Collies, German Shepherds, and Poodles are overrepresented in some reports for intestinal adenocarcinoma [2, 4, 22, 33].

In recent years, there has been an increase in the number of Jack Russell Terriers (JRTs) diagnosed with adenomas and adenocarcinomas of the gastrointestinal tract in Japan [24, 36]. Furthermore, an identical heterozygous germline mutation in the adenomatous polyposis coli $(A P C)$ gene was found in 21 JRTs with gastrointestinal adenomas and adenocarcinomas, suggesting that the disease is equivalent to familial adenomatous polyposis (FAP) in humans [36].

FAP in humans is an autosomal dominant hereditary cancer syndrome caused by a germline heterozygous mutation in the $A P C$ gene, which is known as the gatekeeper tumor suppressor gene for colorectal cancer $[3,6,10,11,17]$. The characteristic feature of human FAP is the emergence of hundreds to thousands of adenomatous polyps distributed throughout the colon and rectum. Polyps generally develop in the early teens, and the lifetime risk of colorectal cancer reaches up to $100 \%$ if left untreated. In patients 
diagnosed with FAP, prophylactic colectomy to prevent future colorectal cancer development is strongly recommended. If advanced colorectal cancer is detected at the time of diagnosis of FAP and colectomy is not indicated, surgery or chemotherapy similar to that used to treat sporadic colorectal cancer is an option. Extracolorectal organs such as the stomach and duodenum are also known to be predisposed to develop various lesions, including adenomas and other cancers.

Adenomas and adenocarcinomas in JRTs appear to have distinct clinical and pathological features compared to other dog breeds $[24,36]$. Some of these features appear to be similar to human FAP, while some other features are dissimilar. The purpose of this retrospective study was to investigate the clinical and histopathological features and prognosis of adenocarcinomas arising in the gastrointestinal tract in JRTs.

\section{MATERIALS AND METHODS}

\section{Study population}

The medical records at the Veterinary Medical Center of the University of Tokyo (VMC-UT) were reviewed to identify dogs that received a diagnosis of gastrointestinal tumors between April 1, 2014, and September 30, 2017. Dogs were eligible for inclusion in the study if they had a histological diagnosis of adenocarcinoma within the gastrointestinal tract, including the stomach, small intestine, or large intestine. Dogs with epithelial tumors other than adenocarcinoma and dogs with mesenchymal or hematopoietic tumors were excluded from the study.

\section{Data collection}

Data obtained from the medical record of each dog included age, sex, breed, site of lesion(s), and histopathological diagnosis. To describe the clinical features of the JRTs with adenocarcinoma, more detailed information was retrieved from the medical record of each dog. These data included clinical signs, physical examination findings, complete blood cell count (CBC) and blood biochemistry results, and results of diagnostic imaging, including thoracic and abdominal radiography, abdominal ultrasonography, and systemic computed tomography $(\mathrm{CT})$, where available.

\section{Histopathological examination}

Samples were obtained endoscopically or surgically in each dog, fixed in 10\% neutral buffered formalin, and routinely embedded in paraffin. The paraffin blocks were cut into $4 \mu \mathrm{m}$ thick sections and stained with hematoxylin and eosin (HE). The specimens were examined by one of two pathologists certified by the Japanese College of Veterinary Pathology (James K. Chambers and Kazuyuki Uchida). Each specimen was diagnosed according to the "WHO histological classification of tumors of the alimentary system of domestic animals" [8].

\section{Statistical analysis}

Categorical variables were compared using Fisher's exact test. Odds ratios (ORs) and 95\% confidence intervals (CIs) were calculated using logistic regression analysis. Survival time was defined as the period from the date of referral to the date of death in each dog. For analysis, dogs were censored if they were alive at the time of analysis or lost to follow-up. Dogs that died from causes unrelated to tumor progression were also censored. Kaplan-Meier curves and 2-sided log-rank tests were used to compare survival data. Values of $P<0.05$ were considered statistically significant. All statistical analyses were performed using commercial statistical software (JMP pro 15.1.0, SAS Institute, Cary, NC, USA).

\section{RESULTS}

\section{Epidemiology of canine adenoma and adenocarcinoma}

Between April 2014 and September 2017, a total of 6,518 dogs, including 134 JRTs, were referred to the VMC-UT. Of these, 46 dogs, including 7 JRTs, were diagnosed with adenocarcinoma, representing an incidence of $0.70 \%$. When limited to JRT, the incidence of adenocarcinoma was calculated to be $5.2 \%$.

Of the dogs diagnosed with adenocarcinoma, lesions were present in the stomach in 12 dogs (26.1\%), in the small intestine in nine dogs (19.6\%), and in the large intestine in $23 \mathrm{dogs}(50.0 \%)$. One dog had lesions in the stomach and small intestine concurrently, and the remaining dog, a JRT, had lesions in the stomach and large intestine. The median age of dogs with adenocarcinoma was 11.3 years (range: 2.8 to 18.6 years). There was no apparent sex difference in dogs with adenocarcinoma, with 24 males (17 castrated) and 22 females (15 spayed). The breeds that represented more than one case in descending order were the Miniature Dachshund ( $\mathrm{n}=13)$, JRT $(\mathrm{n}=7)$, Toy Poodle $(\mathrm{n}=6)$, Shih Tzu $(\mathrm{n}=2)$, and Chihuahua $(\mathrm{n}=2)$. Among those, the JRT was identified as a breed at increased risk of developing adenocarcinoma (OR: 8.97, 95\% CI: 3.94 to 20.43, $P=0.0001$ ). Of the other breeds, only the Miniature Dachshund was found to have a significantly higher risk of adenocarcinoma (OR: $2.06,95 \%$ CI: 1.08 to 3.92, $P=0.0410)$.

\section{Clinical features of adenocarcinoma in JRTS}

Seven JRTs were diagnosed with adenocarcinoma (Table 1). Of these, four dogs had pyloric lesions, two dogs had rectal lesions, and one dog had concurrent pyloric and rectal lesions. Four dogs had multiple, circumferential masses, and three dogs had 1 or 2 solitary, sessile masses. The median age of the 7 JRTs with adenocarcinoma was 9.1 years (range: 6.1 to 15.5 years). Five of the 
Table 1. Sites and macroscopic appearance of lesions in each Jack Russell Terrier with adenocarcinoma

\begin{tabular}{cccll}
\hline Case number & Age (years) & Sex $^{\text {a) }}$ & Site(s) & Macroscopic appearance \\
\hline 1 & 6.8 & M & Stomach (pylorus) & Multiple, circumferential masses \\
2 & 9.1 & M & Stomach (pylorus) & Multiple, circumferential masses \\
3 & 13.9 & M & Stomach (pylorus) & Multiple, circumferential masses \\
4 & 15.5 & FS & Stomach (pylorus) & Multiple, circumferential masses \\
5 & 6.1 & MC & Large intestine (rectum) & 1 solitary, sessile mass \\
6 & 9.9 & FS & Large intestine (rectum) & 1 solitary, sessile mass \\
7 & 7.8 & M & Stomach (pylorus) & 2 solitary, sessile masses \\
& & & Large intestine (rectum) & 2 solitary, sessile masses \\
\hline
\end{tabular}

a) Sex; M: male, FS: female spayed, MC: male castrated.

dogs were male ( 1 castrated), and two dogs were female (all spayed). Three of the JRTs (cases 1, 3, and 4) had a prior history of gastric adenocarcinoma and had undergone surgical resection when they were aged 2.9, 3.4, and 7.0 years, respectively, at the time of the previous diagnosis. Case 5 had previously been diagnosed with small intestinal adenoma and undergone surgery at the age of 2.2 years. Case 3 was the sire of case 1 . No pedigree information was available for the other dogs.

Clinical signs in the JRTs were related to the site of their lesions. Vomiting $(n=4)$, weight loss $(n=4)$, diarrhea $(n=2)$, anorexia $(n=1)$, and melena $(n=1)$ were observed in five dogs with gastric adenocarcinoma. In the three dogs with rectal adenocarcinoma, hematochezia was the chief clinical sign and the masses were palpable on rectal examination.

$\mathrm{CBC}$ and blood biochemistry were performed in all 7 JRTs. Characteristic abnormalities in those dogs were associated with gastrointestinal bleeding and inflammation caused by the lesions, including mild anemia ( $\mathrm{n}=2,33 \%$ and $36 \%$, reference range (RR): 37 to $62 \%$ ), leukocytosis ( $n=4$, median: $23,500 / \mu 1$, range: 17,360 to $25,880 / \mu 1, \mathrm{RR}: 5,050$ to $16,760 / \mu 1$ ), thrombocytosis ( $\mathrm{n}=3$, median: $535,000 / \mu 1$, range: 498,000 to $722,000 / \mu 1$, RR: 148,000 to $464,000 / \mu 1$ ), hypoproteinemia ( $\mathrm{n}=1,4.8 \mathrm{~g} / \mathrm{dl}, \mathrm{RR}: 5.0$ to $7.2 \mathrm{~g} /$ $\mathrm{dl}$ ), hypoalbuminemia ( $\mathrm{n}=3$, median: $2.3 \mathrm{~g} / \mathrm{dl}$, range: 2.2 to $2.4 \mathrm{~g} / \mathrm{dl}$, RR: 2.6 to $4.0 \mathrm{~g} / \mathrm{dl}$ ), and mild elevation of C-reactive protein ( $\mathrm{n}=3$, median: $1.0 \mathrm{mg} / \mathrm{dl}$, range: $1.02 .6 \mathrm{mg} / \mathrm{dl}$, RR: 0 to $0.7 \mathrm{mg} / \mathrm{dl}$ ).

Thoracic radiography was performed in all 7 JRTs, with no dog showing significant changes. Abdominal radiography was performed in three dogs (cases 1, 4, and 5), and a gastric mass was revealed in two of these dogs. Abdominal ultrasonography was performed in all dogs except for one dog (case 6), with severe thickening of the gastric wall or a gastric mass observed in five dogs. In dogs with rectal adenocarcinoma, the rectal mass in each dog could not be detected by abdominal radiography or ultrasonography. Five dogs (cases 2-4, 6, and 7) underwent a whole-body CT scan. A thickened gastric wall at the pylorus with multiple polypoid lesions was found in three dogs, and two solitary masses in the pylorus were found in another dog. One or two solitary masses were found in the rectum in two dogs. On CT, gastric and rectal lesions of each dog were confirmed to be located mainly in the mucosal layer of the gastrointestinal tract, with contrast enhancement effect. An enlarged pancreaticoduodenal lymph node, $1 \mathrm{~cm}$ in diameter, was identified in one dog (case 2) by abdominal ultrasonography and CT. However, no lesions suggesting metastasis were detected by the aforementioned imaging techniques in any other dog. Of the 7 JRTs with adenocarcinomas, samples for histopathological examination were obtained by endoscopic biopsy forceps in two dogs, by endoscopic polypectomy in one dog, and by surgical excision in four dogs.

\section{Histopathology of adenocarcinomas in JRTS}

All gastric adenocarcinomas ( $5 \mathrm{dogs})$ were composed of tubular or papillary structures, which resulted in the diagnosis of either tubular, papillary, or tubulopapillary adenocarcinoma. All rectal adenocarcinomas (3 dogs) had tubular or acinar structures and were diagnosed as either tubular or acinar adenocarcinoma. No JRT had a diagnosis of signet-ring cell carcinoma or mucinous adenocarcinoma. Most of the tumor cells were generally confined within the mucosal epithelium, with minimal invasion to surrounding tissues. All the JRTs were diagnosed with adenocarcinomas based on the findings of irregular stratification of mucosal epithelium, disruption of basement membrane structures, and invasion into the stroma. However, these findings were not severe and were only observed in some of the lesions. Partial involvement of the submucosa and muscularis was observed in only one of the four cases that underwent full-thickness biopsy (case 2). Mitosis was rarely observed in one dog, occasionally in four dogs, and frequently in two dogs.

The enlarged pancreaticoduodenal lymph node detected in case 2 by imaging was resected during surgery. Histopathological examination of the lymph node did not reveal the presence of tumor cells, and it was determined to be reactive hyperplasia.

\section{Treatment of JRTs with adenocarcinoma}

The 7 JRTs underwent a wide variety of treatments (Table 2). Gastrectomy (Billroth I) was performed twice in one dog (case 2), but recurrences were confirmed 280 days and 444 days after the first and second surgeries, respectively. Rectal full-thickness pullthrough was performed in two dogs (cases 5 and 6), with no recurrence until 131 days and 1,245 days after surgery, respectively. Palliative mucosal resection with a gastrostomy to debulk the mucosal mass lesions was performed in three cases, because the pyloric lesions were so extensive that curative surgery was not possible; two of which showed recurrence 87 days and 132 days after surgery (cases 2 and 3), respectively. No recurrence was confirmed up to 83 days after the surgery in the remaining case 
Table 2. Treatments and survival times in each Jack Russell Terrier with adenocarcinoma

\begin{tabular}{|c|c|c|c|c|}
\hline $\begin{array}{l}\text { Case } \\
\text { number }\end{array}$ & Surgical and/or endoscopic treatment & Medical treatment & Outcome & $\begin{array}{l}\text { Survival time } \\
\text { (days) }\end{array}$ \\
\hline 1 & Day 22: mucosal resection of the pylorus & Day 1-104: prednisolone & Alive, without recurrence & $104+$ \\
\hline 2 & $\begin{array}{l}\text { Day 61: gastropylorectomy (Billroth I) } \\
\text { Day 355: mucosal resection of the pylorus } \\
\text { Day 511: endoscopic polypectomy } \\
\text { Day 614: gastropylorectomy (Billroth I) } \\
\text { Day 1,064: endoscopic polypectomy, argon plasma coagulation }\end{array}$ & Day 78-614: piroxicam, cyclophosphamide & $\begin{array}{l}\text { Died of gallbladder rupture, } \\
\text { without recurrence }\end{array}$ & 1,366 \\
\hline 3 & Day 19: mucosal resection of the pylorus & Day 1-234: budesonide & Died of tumor progression & 234 \\
\hline 4 & None & Day 1-374: piroxicam & Died of tumor progression & 374 \\
\hline 5 & $\begin{array}{l}\text { Day 504: endoscopic polypectomy } \\
\text { Day 688: endoscopic polypectomy } \\
\text { Day 839: endoscopic polypectomy } \\
\text { Day 1,326: rectal full-thickness pull-through }\end{array}$ & $\begin{array}{l}\text { Day 1-314: piroxicam } \\
\text { Day 315-470: piroxicam, cyclophosphamide } \\
\text { Day 688-874: piroxicam } \\
\text { Day } 875-1,014 \text { : piroxicam, chlorambucil } \\
\text { Day 1,015-1,308: pirocicam, toceranib }\end{array}$ & Alive, without recurrence & $1,569+$ \\
\hline 6 & Day 6: rectal full-thickness pull-through & $\begin{array}{l}\text { Day 22-281: carprofen, cyclophosphamide } \\
\text { Day 282-673: piroxicam }\end{array}$ & Alive, without recurrence & $1,250+$ \\
\hline 7 & Day 1: endoscopic polypectomy & $\begin{array}{l}\text { Day 78-863: piroxicam } \\
\text { Day 864-967: prednisolone }\end{array}$ & Alive, with recurrence & $967+$ \\
\hline
\end{tabular}

(case 1). All cases underwent surgery were managed under hospitalization after the treatment, and were discharged without major events. Endoscopic polypectomy with or without argon plasma coagulation was performed once in one dog (case 7), twice in one $\operatorname{dog}$ (case 2), and three times in one dog (case 5), but recurrence was confirmed in all attempts except the final treatment in one dog (case 2). The median time to recurrence in dogs that underwent polypectomy was 97.5 days (range: 77 to 305 days). No obvious complications associated with endoscopic treatment were observed in any of the cases. In one dog (case 7), the owner refused any surgical or endoscopic treatment.

All dogs received some form of medication including piroxicam $(0.3 \mathrm{mg} / \mathrm{kg} / \mathrm{day}, \mathrm{n}=4)$, low-dose metronomic cyclophosphamide (15.0 mg/m²/day, $\mathrm{n}=3)$, prednisolone (0.5-1.0 mg/kg/day, $\mathrm{n}=2)$, budesonide $(0.2 \mathrm{mg} / \mathrm{kg} / \mathrm{day}, \mathrm{n}=1)$, carprofen $(4.3 \mathrm{mg} / \mathrm{kg} / \mathrm{day}$, $\mathrm{n}=1)$, chlorambucil $\left(3.0 \mathrm{mg} / \mathrm{m}^{2} /\right.$ day, $\left.\mathrm{n}=1\right)$, and/or toceranib $(2.6 \mathrm{mg} / \mathrm{kg} \mathrm{q} 48 \mathrm{hr}, \mathrm{n}=1)$. Although most of these drugs showed only partial reduction in tumor size or transient improvement of clinical signs, the administration of toceranib resulted in the transient disappearance of the macroscopic lesions in one dog (case 5). Sterile cystitis was observed in one dog received low-dose metronomic cyclophosphamide (case 6); the symptom resolved with discontinuation of the medication.

\section{Clinical outcomes of JRTs with adenocarcinoma}

Surgery or endoscopic treatment were performed in six JRTs. Four dogs underwent surgery or endoscopic treatment only once; no recurrence was confirmed in two of them (case 1 and 6), but recurrence was confirmed in the other two dogs (case 3 and 7). The remaining two dogs (case 2 and 5) had repeated recurrences after multiple procedures, but no recurrences were observed after the fourth to fifth surgical or endoscopic treatment. One dog diagnosed with gastric adenocarcinoma (case 3 ) died because of tumor progression. The cause of death was pyloric obstruction and refractory vomiting due to the growth of gastric masses, with a survival time of 234 days. The dog that did not undergo surgery or endoscopic treatment (case 4) died 374 days later also because of pyloric obstruction, and gastric bleeding associated with tumor progression. The other cases had a prolonged prognosis regardless of presence and frequency of recurrent disease, with long-term survival of up to 1,366 days in dogs with gastric adenocarcinoma, and up to 1,569 days or more in dogs with rectal adenocarcinoma. Re-staging was performed in each case in consideration of the site of tumor development and clinical symptoms at the time of regular examination. The intervals and methods of the re-staging were not consistent among the cases. During the study period, no dog was confirmed to have lesions outside of the gastrointestinal tract, suggesting no evidence of metastasis.

\section{Comparison of prognosis between JRTs and other breeds}

The median follow-up time for all 46 dogs diagnosed with gastrointestinal adenocarcinoma was 248 days (range: 2 to 1,973 days). By the time of the final analysis, 22 dogs, including two JRTs, had died due to tumor progression, while six dogs, including one JRT, had died from other causes. The remaining 18 dogs were alive on the day of their last visit. No dog was euthanized. The overall median survival time (MST) for the $14 \mathrm{dogs}$ with gastric adenocarcinoma was 105 days (range: 2 to 1,366 days). The MST for five of the JRTs could not be determined because more than half of the cases remained alive, while the MST for the nine non-JRT dogs was 34 days (range: 2 to 1,779 days). The difference in MST between the JRTs and non-JRT dogs with gastric adenocarcinoma was significant $(P=0.0220)$ (Fig. 1). For adenocarcinoma in the large intestine, the overall MST for 24 dogs was 1,973 days (range: 46 to 1,973 days). The MST for three of the JRTs could not be determined because all cases remained alive. The MST for the 21 non-JRT dogs was 1,973 days (range: 46 to 1,973 days). There was no significant difference between the two groups $(P=0.2798)$. The MST for six dogs with adenocarcinoma in the small intestine, all of which were non-JRT dogs, was 379 days (range: 16 to 1,322 days). 


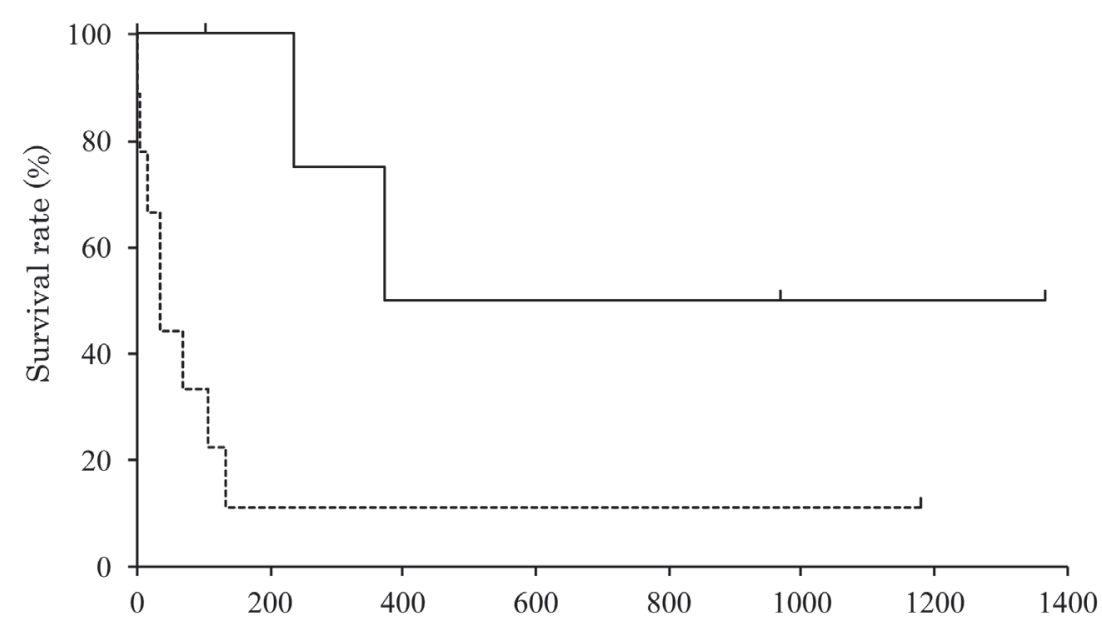

Survival time (days)

Fig. 1. Kaplan-Meier survival curves for dogs with adenocarcinoma of the stomach. The median survival time (MST) for five of the Jack Russell Terriers (JRTs, solid line) could not be determined because more than half of the cases remained alive. The MST for nine non-JRT dogs (dashed line) was 34 days (range: 2 to 1,779 days). The MST for JRTs was significantly longer than for non-JRT breeds $(P=0.0220)$.

\section{DISCUSSION}

Canine gastric adenocarcinoma typically has a poor prognosis. The MST of 10 dogs with surgically resected gastric adenocarcinoma was reported to be as short as 72 days [7]. A recent study reported a better prognosis in 40 dogs with gastric adenocarcinoma that underwent surgery, with a median progression-free interval of 54 days and an MST of 178 days [1]. This study, however, demonstrated that JRTs with gastric and/or rectal adenocarcinoma had a prolonged prognosis compared with the other dog breeds. Of the JRTs with gastric adenocarcinoma, more than half survived beyond 1 year despite a high recurrence rate after surgery or endoscopic treatment. For the JRTs with rectal adenocarcinoma, survival for 2.5 to 4 years or more after surgery or endoscopic treatment was confirmed. Furthermore, in non-JRT dogs, gastric adenocarcinoma had a shorter survival time compared to colorectal adenocarcinoma, whereas in JRT, a relatively prolonged survival was confirmed even for gastric adenocarcinoma. These results indicate that gastrointestinal adenocarcinomas in JRTs may have a different clinical course than sporadic gastrointestinal adenocarcinomas found in other dog breeds.

The reasons for prognostic differences between the JRTs and the other breeds could not be determined, but several factors were considered. The first possibility is a difference in histological subtype. Canine gastric adenocarcinoma is generally classified as signetring cell carcinoma or mucous adenocarcinoma, however all gastric adenocarcinomas in the JRTs in this report had a growth pattern consistent with tubular, papillary, or tubulopapillary adenocarcinoma [5, 8], consistent with the results of a previous report [24]. In humans, histologic subtype based on WHO classification is known to be a prognostic factor, wherein signet-ring cell, mucinous, and undifferentiated subtypes are considered to have a poorer prognosis compared to tubular and papillary subtypes [15]. Although the clinical and prognostic significance of histologic subtype in canine gastric adenocarcinoma has not been clearly demonstrated, a case report of a dog diagnosed with gastric tubular adenocarcinoma showed survival as long as 30 months after surgery [14].

Another possible reason could be that adenocarcinomas in JRTs are comparable to human adenomas and therefore have a better prognosis. This contradiction could have originated from differences in the diagnostic criteria for tumors in humans and dogs. Histopathological examination of the adenocarcinomas in the JRTs revealed that the lesions were mainly confined to the mucosal epithelium and were poorly invasive into the submucosa and muscularis. In such a situation, the distinction between adenoma and adenocarcinoma largely depends on the subjective diagnosis of the pathologist. Conversely, since invasion of the submucosa is regarded as essential for diagnosing adenocarcinoma in the WHO classification of tumors in humans, most of the lesions of the JRTs in our study could be diagnosed as adenomas rather than adenocarcinomas [34]. These characteristic histopathological findings in adenocarcinoma of JRT might have been associated with a low incidence of metastasis outside the gastrointestinal tract. Metastasis of canine gastric adenocarcinoma has classically been reported to occur at a high rate, with 70 to $90 \%$ at the time of diagnosis $[7,22,29,30]$. In contrast, none of the JRTs with gastric adenocarcinoma included in our study had metastasis detected at the time of diagnosis or during the course of treatment. The lesions in JRTs with gastric adenocarcinoma were poorly invasive and localized within the mucosal epithelium, which may have been associated with a low metastasis rate. Regarding adenocarcinoma of the large intestine, there was no significant difference in prognosis between the JRTs and the other breeds, but it was possible that the statistical power was weak due to the small number of cases.

Four out of five cases of JRTs with gastric adenocarcinoma were characterized by multiple and widespread lesions, which made surgical resection difficult. In one case, radical surgical resection was attempted twice, but recurrence occurred after each treatment. 
In contrast, all three cases of JRTs with rectal adenocarcinoma had 1 or 2 solitary lesions. In two of those cases, complete resection was achieved by full-thickness rectal pull-through, and recurrence was not observed during the study period. In human FAP, total colectomy with ileorectal anastomosis or proctocolectomy with ileal-pouch-anal anastomosis is recommended for the prevention of colorectal adenocarcinoma development, and extensive removal of all areas of the colon and rectum that are predisposed to tumor development is considered important [10, 11, 17]. In dogs, the rectal full-thickness pull-through technique has been reported to be a useful surgical method that enables wide resection of adenocarcinomas of the rectum or distal colon [19, 20]. The present study suggests that aggressive surgical resection of the rectum, which is a common site for rectal adenocarcinoma in JRTs, is useful for radical treatment. However, it should be noted that lesions can arise not only in the rectum, but also concurrently in the stomach.

Among the JRTs in our study, only two cases with gastric adenocarcinoma died, and the cause of death in those cases was pyloric obstruction or gastric bleeding associated with the growth of gastric masses. In other cases, long-term survival occurred regardless of the type of surgery or endoscopic treatment, the number of recurrences, or the presence or absence of eventual recurrence. These results indicate that although radical surgical resection is ideal for treatment, in cases where complete resection is impossible, palliative surgical or endoscopic treatment to debulk the masses may play a role in preventing gastrointestinal obstruction or bleeding and improve the prognosis.

In this study, a wide variety of drugs were used to treat macroscopic lesions and as adjuvant therapy after surgery. As the details of treatment were not uniform, the efficacy of each drug could not be objectively analyzed. Piroxicam, a non-steroidal anti-inflammatory drug (NSAID), was prescribed in most cases. Several studies in humans have demonstrated that cyclooxygenase (COX), especially COX-2, is overexpressed in colorectal cancers and contributes to tumor development [27, 31]. Celecoxib, a selective COX-2 inhibitor, is known to be the first chemoprevention medication approved by the Food and Drug Administration for the treatment of colorectal polyps in patients with FAP [28]. Contrary to the findings in humans, the relevance of COX-2 in the pathogenesis of canine gastrointestinal adenocarcinoma has not been clarified $[12,18]$. The significance of COX-2 and the efficacy of NSAIDs for gastrointestinal adenocarcinomas in JRTs needs to be evaluated. It is worth noting that toceranib was effective in 1 JRT with rectal adenocarcinoma. Toceranib is a tyrosine kinase inhibitor approved as a molecular target drug for canine mast cell tumors. In addition to inhibiting KIT, toceranib also inhibits platelet-derived growth factor receptor and vascular endothelial growth factor receptor, and has been reported to have anti-tumor effects against not only mast cell tumors but also a variety of tumors [16]. A recent study in dogs with various adenocarcinomas, including adenocarcinoma of the small intestine, reported that administration of toceranib as a postoperative adjunct therapy significantly extended the time to progression after surgery [35]. Based on the cases in our report and the previous study, further investigation of toceranib as a chemotherapy option for adenocarcinomas in JRTs is warranted.

Similar to a recent report, the present study found that the Miniature Dachshund is also a breed at high risk of developing gastrointestinal adenocarcinoma [24]. Inflammatory polyps of the colon and rectum are prevalent in Miniature Dachshunds in Japan, and these have been shown to potentially progress to colorectal adenomas and adenocarcinomas in later life, which may have influenced the increased incidence of colorectal adenocarcinoma in this breed [9, 21, 23, 32].

Limitations of the present study include its retrospective nature, small sample size, and lack of standardized surgical and medical treatment protocols. Due to the small number of cases included in each surgical, endoscopic, and medical treatment group, it was not possible to objectively assess the prognostic impact of each treatment. Some cases were diagnosed by endoscopic biopsy rather than full-thickness biopsy, which could have affected the results of the histopathological diagnosis. Ideally, all histologic samples would have been reviewed by a single pathologist. Postmortem examinations were not available for any case.

In conclusion, although JRTs are predisposed to gastrointestinal adenocarcinomas, some of the dogs with gastric and rectal adenocarcinomas in this breed were shown to have a potentially prolonged prognosis. Despite extensive lesions leading to incomplete resection and repeated recurrence, the JRTs with gastric adenocarcinoma in the present study were confirmed to have a significantly longer survival time than other breeds. The JRTs with rectal adenocarcinoma survived for a long time after radical surgery or endoscopic treatment. Since gastrointestinal adenocarcinomas in JRTs show distinct characteristics with respect to their clinical features, treatment course, and prognosis, a different surgical and medical treatment plan should be considered compared to the management of gastrointestinal adenocarcinomas in other dog breeds. However, as this study included only nine JRTs, the prognosis of gastrointestinal adenocarcinoma in the JRT should be further investigated in future studies involving larger numbers of patients.

POTENTIAL CONFLICTS OF INTEREST. The authors have nothing to disclose.

\section{REFERENCES}

1. Abrams, B., Wavreille, V. A., Husbands, B. D., Matz, B. M., Massari, F., Liptak, J. M., Cray, M. T., de Mello Souza, C. H., Wustefeld-Janssens, B. G., Oblak, M. L., Su, L. and Selmic, L. E. 2019. Perioperative complications and outcome after surgery for treatment of gastric carcinoma in dogs: a veterinary society of surgical oncology retrospective study of 40 cases (2004-2018). Vet. Surg. 48: 923-932. [Medline] [CrossRef]

2. Adamovich-Rippe, K. N., Mayhew, P. D., Marks, S. L., Selmic, L. E., Culp, W. T., Youello, A. M., Runge, J. J., Holt, D. E., Kass, P. H. and Peauroi, J. R. 2017. Colonoscopic and histologic features of rectal masses in dogs: 82 cases (1995-2012). J. Am. Vet. Med. Assoc. 250: 424-430. [Medline] [CrossRef]

3. Aghabozorgi, A. S., Bahreyni, A., Soleimani, A., Bahrami, A., Khazaei, M., Ferns, G. A., Avan, A. and Hassanian, S. M. 2019. Role of adenomatous polyposis coli (APC) gene mutations in the pathogenesis of colorectal cancer; current status and perspectives. Biochimie 157: 64-71. [Medline] [CrossRef]

4. Church, E. M., Mehlhaff, C. J. and Patnaik, A. K. 1987. Colorectal adenocarcinoma in dogs: 78 cases (1973-1984). J. Am. Vet. Med. Assoc. 191: 727-730. [Medline] 
5. Fonda, D., Gualtieri, M. and Scanziani, E. 1989. Gastric carcinoma in the dog: a clinicopathological study of 11 cases. J. Small Anim. Pract. 30: 353-360. [CrossRef]

6. Gatalica, Z. and Torlakovic, E. 2008. Pathology of the hereditary colorectal carcinoma. Fam. Cancer 7: 15-26. [Medline] [CrossRef]

7. Gualtieri, M., Monzeglio, M. G. and Scanziani, E. 1999. Gastric neoplasia. Vet. Clin. North Am. Small Anim. Pract. 29: 415-440. [Medline] [CrossRef]

8. Head, K. W., Cullen, J. M., Dubielzig, R. R., Else, R. W., Misdrop, W., Patnaik, A. K., Tateyama, S. and van der Gaag, I. 2003. Histological classification of tumors of the alimentary system of domestic animals, 2nd series, vol. IX., Armed Forces Institute of Pathology in cooperation with the American Registry of Pathology and the World Health Organization Collaborating Center for Worldwide Reference on Comparative Oncology, Washington, D.C.

9. Igarashi, H., Ohno, K., Ohmi, A., Tsukamoto, A., Nakashima, K., Fujino, Y., Uchida, K. and Tsujimoto, H. 2013. Polypoid adenomas secondary to inflammatory colorectal polyps in 2 miniature dachshunds. J. Vet. Med. Sci. 75: 535-538. [Medline] [CrossRef]

10. Kanth, P., Grimmett, J., Champine, M., Burt, R. and Samadder, N. J. 2017. Hereditary colorectal polyposis and cancer syndromes: a primer on diagnosis and management. Am. J. Gastroenterol. 112: 1509-1525. [Medline] [CrossRef]

11. Kidambi, T. D., Kohli, D. R., Samadder, N. J. and Singh, A. 2019. Hereditary polyposis syndromes. Curr. Treat. Options Gastroenterol. 17: 650-665. [Medline] [CrossRef]

12. Knottenbelt, C., Mellor, D., Nixon, C., Thompson, H. and Argyle, D. J. 2006. Cohort study of COX-1 and COX-2 expression in canine rectal and bladder tumours. J. Small Anim. Pract. 47: 196-200. [Medline] [CrossRef]

13. Koterbay, A. M., Muthupalani, S., Fox, J. G. and McNiel, E. A. 2020. Risk and characteristics of gastric carcinoma in the chow chow dog. Can. Vet. J. 61: 396-400. [Medline]

14. Lee, H. C., Kim, J. H., Jee, C. H., Lee, J. H., Moon, J. H., Kim, N. H., Sur, J. H., Cho, K. W., Kang, B. T., Ha, J. and Jung, D. I. 2014. A case of gastric adenocarcinoma in a Shih Tzu dog: successful treatment of early gastric cancer. J. Vet. Med. Sci. 76: 1033-1038. [Medline] [CrossRef]

15. Liu, L., Wang, Z. W., Ji, J., Zhang, J. N., Yan, M., Zhang, J., Liu, B. Y., Zhu, Z. G. and Yu, Y. Y. 2013. A cohort study and meta-analysis between histopathological classification and prognosis of gastric carcinoma. Anticancer. Agents Med. Chem. 13: 227-234. [Medline] [CrossRef]

16. London, C., Mathie, T., Stingle, N., Clifford, C., Haney, S., Klein, M. K., Beaver, L., Vickery, K., Vail, D. M., Hershey, B., Ettinger, S., Vaughan, A., Alvarez, F., Hillman, L., Kiselow, M., Thamm, D., Higginbotham, M. L., Gauthier, M., Krick, E., Phillips, B., Ladue, T., Jones, P., Bryan, J., Gill, V., Novasad, A., Fulton, L., Carreras, J., McNeill, C., Henry, C. and Gillings, S. 2012. Preliminary evidence for biologic activity of toceranib phosphate $\left(\right.$ Palladia $\left.^{\circledR}\right)$ in solid tumours. Vet. Comp. Oncol. 10: 194-205. [Medline] [CrossRef]

17. Ma, H., Brosens, L. A. A., Offerhaus, G. J. A., Giardiello, F. M., de Leng, W. W. J. and Montgomery, E. A. 2018. Pathology and genetics of hereditary colorectal cancer. Pathology 50: 49-59. [Medline] [CrossRef]

18. McEntee, M. F., Cates, J. M. and Neilsen, N. 2002. Cyclooxygenase-2 expression in spontaneous intestinal neoplasia of domestic dogs. Vet. Pathol. 39: 428-436. [Medline] [CrossRef]

19. Morello, E., Martano, M., Squassino, C., Iussich, S., Caccamo, R., Sammartano, F., Zabarino, S., Bellino, C., Pisani, G. and Buracco, P. 2008. Transanal pull-through rectal amputation for treatment of colorectal carcinoma in 11 dogs. Vet. Surg. 37: 420-426. [Medline] [CrossRef]

20. Nucci, D. J., Liptak, J. M., Selmic, L. E., Culp, W. T., Durant, A. M., Worley, D., Maritato, K. C., Thomson, M., Annoni, M., Singh, A., Matz, B., Benson, J. and Buracco, P. 2014. Complications and outcomes following rectal pull-through surgery in dogs with rectal masses: 74 cases (2000-2013). J. Am. Vet. Med. Assoc. 245: 684-695. [Medline] [CrossRef]

21. Ohmi, A., Tsukamoto, A., Ohno, K., Uchida, K., Nishimura, R., Fukushima, K., Takahashi, M., Nakashima, K., Fujino, Y. and Tsujimoto, H. 2012. A retrospective study of inflammatory colorectal polyps in miniature dachshunds. J. Vet. Med. Sci. 74: 59-64. [Medline] [CrossRef]

22. Patnaik, A. K., Hurvitz, A. I. and Johnson, G. F. 1977. Canine gastrointestinal neoplasms. Vet. Pathol. 14: 547-555. [Medline] [CrossRef]

23. Saito, T., Chambers, J. K., Nakashima, K., Uchida, E., Ohno, K., Tsujimoto, H., Uchida, K. and Nakayama, H. 2018. Histopathologic features of colorectal adenoma and adenocarcinoma developing within inflammatory polyps in Miniature Dachshunds. Vet. Pathol. 55: 654-662. [Medline] [CrossRef]

24. Saito, T., Nibe, K., Chambers, J. K., Uneyama, M., Nakashima, K., Ohno, K., Tsujimoto, H., Uchida, K. and Nakayama, H. 2020. A histopathological study on spontaneous gastrointestinal epithelial tumors in dogs. J. Toxicol. Pathol. 33: 105-113. [Medline] [CrossRef]

25. Scanziani, E., Giusti, A. M., Gualtieri, M. and Fonda, D. 1991. Gastric carcinoma in the Belgian shepherd dog. J. Small Anim. Pract. 32: 465-469. [CrossRef]

26. Seim-Wikse, T., Jörundsson, E., Nødtvedt, A., Grotmol, T., Bjornvad, C. R., Kristensen, A. T. and Skancke, E. 2013. Breed predisposition to canine gastric carcinoma--a study based on the Norwegian canine cancer register. Acta Vet. Scand. 55: 25. [Medline] [CrossRef]

27. Sinicrope, F. A. 2006. Targeting cyclooxygenase-2 for prevention and therapy of colorectal cancer. Mol. Carcinog. 45: 447-454. [Medline] [CrossRef]

28. Steinbach, G., Lynch, P. M., Phillips, R. K., Wallace, M. H., Hawk, E., Gordon, G. B., Wakabayashi, N., Saunders, B., Shen, Y., Fujimura, T. Su, L. K., Levin, B., Godio, L., Patterson, S., Rodriguez-Bigas, M. A., Jester, S. L., King, K. L., Schumacher, M., Abbruzzese, J., DuBois, R. N., Hittelman, W. N., Zimmerman, S., Sherman, J. W. and Kelloff, G. 2000. The effect of celecoxib, a cyclooxygenase-2 inhibitor, in familial adenomatous polyposis. N. Engl. J. Med. 342: 1946-1952. [Medline] [CrossRef]

29. Sullivan, M., Lee, R., Fisher, E. W., Nash, A. S. and McCandlish, I. A. 1987. A study of 31 cases of gastric carcinoma in dogs. Vet. Rec. 120: 79-83. [Medline] [CrossRef]

30. Swann, H. M. and Holt, D. E. 2002. Canine gastric adenocarcinoma and leiomyosarcoma: a retrospective study of 21 cases (1986-1999) and literature review. J. Am. Anim. Hosp. Assoc. 38: 157-164. [Medline] [CrossRef]

31. Thun, M. J. and Heath, C. W. Jr. 1995. Aspirin use and reduced risk of gastrointestinal tract cancers in the American Cancer Society prospective studies. Prev. Med. 24: 116-118. [Medline] [CrossRef]

32. Uchida, E., Chambers, J. K., Nakashima, K., Saito, T., Ohno, K., Tsujimoto, H., Nakayama, H. and Uchida, K. 2016. Pathologic features of colorectal inflammatory polyps in Miniature Dachshunds. Vet. Pathol. 53: 833-839. [Medline] [CrossRef]

33. Valerius, K. D., Powers, B. E., McPherron, M. A., Hutchison, J. M., Mann, F. A. and Withrow, S. J. 1997. Adenomatous polyps and carcinoma in situ of the canine colon and rectum: 34 cases (1982-1994). J. Am. Anim. Hosp. Assoc. 33: 156-160. [Medline] [CrossRef]

34. WHO Classification of Tumours Editorial Board. 2019. Digestive System Tumours: WHO Classification of Tumours, 5th ed., vol. 2, International Agency for Research on Cancer, Lyon.

35. Yamazaki, H., Tanaka, T., Mie, K., Nishida, H., Miura, N. and Akiyoshi, H. 2020. Assessment of postoperative adjuvant treatment using toceranib phosphate against adenocarcinoma in dogs. J. Vet. Intern. Med. 34: 1272-1281. [Medline] [CrossRef]

36. Yoshizaki, K., Hirata, A., Nishii, N., Kawabe, M., Goto, M., Mori, T. and Sakai, H. 2020. Familial adenomatous polyposis in dogs: hereditary gastrointestinal polyposis in Jack Russell Terriers with germline APC mutations. Carcinogenesis. doi: 10.1093/carcin/bgaa045 (in press). 